\title{
APRENDIZAGEM DA LEITURA E DA ESCRITA À LUZ DA PSICOLINGUÍSTICA GENÉTICA
}

\author{
Maria da Graça L. C. Pinto ${ }^{1^{\star}}$ \\ ${ }^{1}$ Faculdade de Letras da Universidade do Porto, Porto, Portugal
}

\begin{abstract}
Resumo
É objetivo deste texto mostrar que a aprendizagem do oral e da escrita assenta em bases cognitivas, sem subestimar aspetos de ordem social e neurológica. Justifica-se assim que seja lido na ótica da psicolinguística genética, que dá especial realce ao desenvolvimento cognitivo que sustenta a linguagem oral e escrita. A configuração dada ao texto procura evidenciar as condições necessárias a uma entrada na escrita com o sucesso desejado, que vão do domínio das noções de número e de classe e respetivas relações de equivalência e de inclusão, à capacidade de descentração cognitiva que acompanha a abstração indispensável à simbolização que está na origem da iniciação ao código fonográfico. Consta este texto de duas partes: a primeira mais voltada para noções teóricas sem as quais seria difícil entender a perspetiva adotada e a segunda mais prática, documentada por uma bateria de testes que visa avaliar a criança à entrada na escola, tendo em vista os aspetos elencados.

Palavras-chave: Família; Pré-escola; Leitura e Escrita; Abstração; Simbolização
\end{abstract}

\section{LEARNING TO READ AND WRITE IN LIGHT OF GENETIC PSYCHOLINGUISTICS}

Abstract

The aim of this paper is to show that learning to speak and write is based on cognitive foundations, apart from the social and neurological aspects which should not be underestimated. The paper should thus be read from the perspective of genetic psycholinguistics, which places special emphasis on the cognitive development that underpins oral and written language. I intend to highlight the conditions that are required for successful entry into writing, ranging from mastery of the notions of number and class and their relationships of equivalence and inclusion, to the ability for cognitive decentralisation that accompanies abstraction, which is indispensable to

\footnotetext{
* Maria da Graça Lisboa Castro Pinto é Professora Catedrática da Faculdade de Letras da Universidade do Porto (FLUP) desde 1991. Obteve o grau de doutor em 1984 em Linguística Aplicada (Psicoliguística e Neurolinguística) pela Universidade do Porto, orientada por Hermine Sinclair. É membro do Comité Científico de diversas revistas estrangeiras da sua área e membro honorário da International Society of Applied Psycholinguistics desde 2014. Dirige a revista Linguarum Arena. Revista de Estudos em Didática de Línguas da Universidade do Porto desde 2010, tendo sido diretora da revista Linguística. Revista de Estudos Linguísticos da Universidade do Porto de 2006 a 2009. Interessa-se, entre outros, pela aquisição e processamento da linguagem, pela leitura, pela escrita-composição, pela escrita científica e pelo efeito da literacia no envelhecimento cognitivo. Seu e-mail é: mgraca@letras.up.pt. Registro ORCID: http://orcid.org/0000-0002-4842-991X.
} 
the symbolisation that is at the origin of the phonographic code. This paper consists of two parts: the first is focused on theoretical notions without which it would be difficult to understand the perspective adopted, and the second is more practical, documented by a battery of tests that aim to evaluate the child upon entry into school, considering the aspects listed. Keywords: Family; Preschool; Reading and Writing; Abstraction; Symbolisation 


\section{Apontamento de abertura}

Esta breve abertura mais não é do que uma porta de entrada para explorar o objetivo do presente texto que, como ficou exarado no resumo,visa mostrar que a aprendizagem do oral e da escrita assenta em bases cognitivas, sem subestimar aspetos de ordem social e neurológica, bem como de natureza afetiva e emocional. A escolha, para tal fim, de uma abordagem psicolinguística genética justifica-se na medida em que será a que melhor procura explicar o que sustenta cognitivamente os desempenhos verbais na criança, no caso concreto os que se reportam à linguagem escrita.

Um texto com um título que anuncia, numa projeção catafórica, uma aproximação à linguagem escrita firmada na psicolinguística genética e que começa por uma história curiosa, por uma "anecdote", como dirão anglófonos e francófonos, parecerá insólito. Acontece que será tudo menos excêntrico. Colocar a dita área disciplinar como cobertura para o facto descrito concorre antes para se ver como importa criar na criança, a fim de que esta possa lidar bem com a leitura e a escrita, uma "[b]onne organisation de la représentation spatiotemporelle, sans trouble d'orientation" (GIROLAMI-BOULINIER, 1988, p. 25), que passa, segundo a mesma autora, pela consciência do esquema corporal, pela consciência de uma ordem de vazão e de sucessão no tempo e no espaço, bem como pela consciência da correspondência "espace/temps: gauche-droite/avantaprès" (p. 25). No entanto, interessa reter que a vazão da fala tem efetivamente um antes e um depois, mas esse antes e esse depois não correspondem por sistema, comparativamente ao que se verifica na nossa escrita, à esquerda e à direita: um pequeno/grande pormenor do qual a criança terá de vir a estar ciente para que não surjam generalizações abusivas. Foi seguramente uma generalização deste teor, com origem - tudo leva a crer dadas as circunstâncias - num ato automático e não voluntário/consciente, que motivou o que se narra, em guisa de "anecdote", na secção que segue este apontamento de abertura.

A dita "anecdote" conduz a que se sinta que a aprendizagem da leitura e da escrita não pressupõe só uma abordagem a essas duas habilidades sensu stricto, antes reivindica que se considere o agente dessa aprendizagem num todo. Com efeito, foram anunciadas diferentes consciências e não em exclusivo as de ordem linguística e fonológica, que seriam, numa visão mais simplicista, as únicas que se coadunariam com as aprendizagens alegadas. Por outro lado, já que a perspetiva escolhida para sustentar este texto se enquadra na psicolinguística genética, terá de se expor o que de ordem cognitiva se revela indispensável à leitura e à escrita, ou melhor, o que sustenta o domínio do código grafofonológico e fonográfico.

Busca-se assim dar neste texto o merecido destaque, também com base na bateria de testes de Girolami (2001) - "Contrôle des Aptitudes à la Lecture et à l'Ecriture" (CALE) -, aos fundamentos psicolinguísticos vitais para o esperado rendimento de uma criança que dá os primeiros passos escolares. A tónica colocada nas operações de abstração e de simbolização, na formação de conceitos e em habilidades conducentes a exercícios de pré-leitura e de pré- 
escrita, que familiarizem a criança com o mundo da escrita que a aguarda, não constitui mera casualidade.

Isto posto, não surpreenderá ninguém que este texto também encerre um recado bem direcionado. Consiste essa mensagem na necessidade de se investir numa boa política pré-escolar e na sensibilização dos pais ou familiares para o que representa o desenvolvimento de uma literacia emergente capaz, no intento de o ingresso no $1 .^{\circ}$ ano de escolaridade se desenrolar com naturalidade, tanto no plano intelectual como afetivo e emocional. Um diálogo saudável entre essas duas agências de literacia - Família e Escola - terá de ser aceite como um imperativo por todas as partes envolvidas no processo de iniciação à leitura e à escrita.

Os conceitos espontâneos e científicos: a orientação da fala contagiada pela da escrita

Os estudantes não eram numerosos, mas a sua postura em aula denunciava o interesse que a matéria transmitida lhes incutia. Um dia, porém, irrompeu uma agitação fora do comum. O grande David Pisoni, em estatura e em saber, que mantinha sempre acesa a atenção dos que assistiam às suas aulas de "Linguagem e Cognição", tinha acabado de dizer que a cadeia falada se desenrolava da esquerda para a direita. E os estudantes tinham a razão do seu lado. David Pisoni tinhase deixado guiar por um conceito tudo menos científico de cadeia falada e não pelo que se imaginaria de um especialista na área. A contaminação da fala pela escrita fora fatal mesmo para um professor/investigador da notoriedade de David Pisoni, docente da Universidade de Indiana.

Será que, neste caso, se poderá afirmar que um conceito espontâneo, básico, atraiçoou um conceito científico?

Terá sido obstado o conceito associado à cadeia falada, que se adquire em meio académico, de modo analítico e dedutivo, partindo de um nível mais abstrato/geral para um mais concreto/particular (VYGOTSKY, 1962; PIAGET, 1979), por aquilo a que se chegana esfera conceptual através do desenvolvimento mental espontâneo, mais apoiado na indução, isto é, no que se infere a partir da observação dos fenómenos do quotidiano?

Se tiver sido esse o caso, é possível avançar-se que o que faz prevalecer um tipo de conceitos - o espontâneo/não consciente/não sistemático/da ordem do pré-conceito - relativamente ao outro - científico/consciente/aprendido - não é exclusivamente apanágio da criança em fase inicial das aquisições escolares. $\mathrm{O}$ mesmo pode igualmente ocorrer em indivíduos com formação científica, quando resulta gorada a inibição dos conceitos espontâneos, gerando a sua prevalência relativamente aos aprendidos (MASSON, 2012). 


\section{A formação do conceito e a noção de classe}

A construção da noção de conceito segue em paralelo com a construção da noção de classe e é em função disso que surgem, no que se reporta ao conceito básico, em alternativa à designação espontâneo, as denominações: "não consciente", "não sistemático" e "pré-conceito".

Convém sobretudo frisar a ligação da noção de conceito à noção de classe, passível de conter diferentes (sub)classes, sendo cada uma um elemento de um sistema organizado hierarquicamente. Sem o reconhecimento da existência desse sistema com a organização referida não se poderá ter um controle consciente e deliberado do conceito. Haverá, pois, que esperar pelo momento em que a criança se encontra apta a operar em conformidade para que seja atingida a noção de classe e consequentemente de conceito, isto é, o período das operações concretas, cujo início coincide aproximadamente, dado que se lida sempre com médias etárias, com a idade legislada para a admissão na escolaridade obrigatória.

\section{A relação entre a linguagem e a cognição}

Deverá também aflorar do exposto a existência de uma relação estreita entre linguagem e cognição, elo que se verifica desde a emergência dos primeiros esquemas verbais (PIAGET, 1976). Estes, por sua vez, mediante os mecanismos de assimilação e de acomodação vão preparando a criança para passar do símbolo ao signo e do pré-conceito ao conceito. A noção de conceito anda associada à noção de classe, vista como um sistema de relações hierárquicas ou parte dele, resultante de todo um desenvolvimento intelectual operatório que vai transcorrendo na criança até por volta da idade escolar. Aliado à noção de classe encontra-se também o domínio quer da correspondência um-a-um entre os elementos de dois conjuntos, quer da conservação da sua equivalência numérica, indispensável à instalação consolidada da noção de número. Além da noção de classe, deve ainda relevar-se como requisito básico para chegar ao conceito de número, de importância capital no processo de alfabetização, a capacidade de a criança compreender as relações ordinais (GINSBURG, OPPER, 1979).

Como percepcionar, reter e emitir sequências de ruídos, signos, sons, sílabas e palavras sucessivas, reconhecer ou construir frases simples, e também reconhecer um agora/antes/depois nas atividades básicas do dia a dia, conforme regista Girolami-Boulinier (1988), sem lhes agregar a existência de uma relação ordinal, subordinada à linha do tempo, que se corporiza na linearidade no caso das sequências enumeradas?

\section{A quantidade três e o seu significado}

Note-se que basta a quantidade três para que se estabeleça uma relação ordinal. E por que razão a quantidade três e não outra? Trata-se deveras da quantidade 
mínima que cumpre os requisitos próprios de uma relação ordinal, de uma relação de transitividadequando satisfaz os critérios necessários. Ou seja: todos os elementos terão de ser diferentes. Ademais, o elemento que se encontra entre o maior e o menor da série tem de ser ao mesmo tempo menor do que o elemento maior e maior do que o elemento mais pequeno (GINSBURG, OPPER, 1979), arcando uma posição relativa e não absoluta. Para a criança, esta situação pode resultar difícil quando, por falta da descentração cognitiva necessária (PIAGET, 1979), ela for ainda incapaz de olhar sob prismas diferentes para o mesmo objeto. Essa aptidão passará, contudo, a ser uma realidade quando ela tiver alcançado o período operatório concreto. Nessa etapa do desenvolvimento, a criança atinge a reversibilidade e a reciprocidade quando atua com relações que vê já como recíprocas. O grau de descentração a que chegou faculta-lhe o entendimento das transformações e a reversibilidade do pensamento (GINSBURG, OPPER, 1979).

\section{A perspetiva da psicolinguística genética no atinente ao processamento verbal}

Numa perspetiva psicolinguística genética, epíteto muito na linha da Escola de Piaget, porventura uma psicolinguística mais conhecida por desenvolvimentista, é útil reter o que a criança consegue ou não em matéria de desenvolvimento operatório, motivo pelo qual se torna relevante tudo o que foi mencionado, para poder explicar o desempenho verbal que ela manifesta quando lhe é proposta uma dada tarefa. Terá de se ter bem presente que um estudo psicolinguístico visa sempre explicar os resultados a que se chegou com base no desenho de estudo gizado. E essa explicação terá de contar com as bases psicológicas que estão envolvidas no processamento verbal em análise (SLAMA-CAZACU,2007). Não podem restar dúvidas em quem trabalha na área que a criança reage às tarefas que lhe são apresentadas também em função do seu desenvolvimento operatório. Radica exatamente aí o interesse da pesquisa psicolinguística, ou melhor, não basta mostrar o que a criança já adquiriu ou ainda não adquiriu no plano da linguagem. Espera-se também uma explicação para o desempenho observado.

\section{Luria e a visão de túnel do especialista}

É inconcebível não subscrever o pensamento de Luria quando se opta por um estudo não superficial do processamento da linguagem, em qualquer momento da existência. Escreve, então, Vocate (1987, p. 151) sobre o que Luria pensava: "The tunnel-vision of the 'specialist' was viewed by Luria as being incapable of the theoretical scope mandated by the complexity of mental functioning." Essa visão de túnel constante do trecho de Vocate também não se compadece com a exigida por quem se decidir pelo estudo da aquisição da linguagem e da aprendizagem da leitura e da escrita numa ótica psicolinguística.

Pese embora a importância que também deve ser atribuída às bases neurológicas da linguagem, é mais do que legítimo lembrar a posição de 
Slama-Cazacu, posto que esta autora também enfatiza essa visão multímoda do especialista, e definitivamente não de túnel, quando escreve:

O que denominaríamos (...) de 'sócio-psicolingüistica' é, pois, a $P L$ propriamente dita que toma em consideração a situação da comunicação real, os fatos reais que aí se encontram, as determinantes sociais que aí operam - e que não podem ser ignoradas pela análise da mensagem, a não ser que se corra o risco de cometer distorções mais ou menos graves dos resultados (SLAMA-CAZACU, 1979, p. 62).

\section{A fala e a escrita: a forma de se materializarem no tempo e no espaço}

De regresso à cadeia falada e à escrita, pode dizer-se que tanto uma como outra comportam sequências consubstanciadas por meio de sonoridades na cadeia da fala e por sinais gráficos na escrita. Todavia, essas sequências, não obstante terem de obedecer à linha do tempo, podem ou não seguir direções similares em virtude de cada uma delas oferecer materializações distintas.

Tocou-se numa característica universal da linguagem: a linearidade, que advém de a linguagem se desenrolar no tempo, o que determina, entre outros, a expressão "cadeia falada" (SOKHIN, 1988, p. 380). Recorrendo ao termo "primitivos", muito usado por Piaget e que testemunha bem que o desenvolvimento do ser humano apresenta em estádios iniciais prenúncios do que se verificará depois conceptualmente (GINSBURG, OPPER, 1979), é possível ver nas silabadas proferidas reiteradamente pela criança nos primeiros tempos da sua existência um primitivo da linearidade da linguagem. Ao serviço da repetição de sílabas está a inevitável assimilação funcional, dependente por sua vez, para o seu aprimoramento, da acomodação particularizante. Relativamente à aquisição da língua, o particular a que se alude tem a ver com a língua a que a criança está exposta, essencialmente por via auditiva e que lhe serve de modelo. São passos como estes que comprovam que a língua também é um objeto de conquista pela criança. Um objeto muito complexo, conforme previne Hermine Sinclair (1974), visto que não se destina apenas a ser conquistado por via indutiva para chegar às regras que o governam; ele concorre igualmente, mediante a simbolização que consubstancia, para a conquista dos outros objetos e inclusive para a sua autorreferência.

Não se podeconcordarmais com Elkonin (1988) quandoesteautorescreve: "The development of oral language in the child is a complex and lenghty task that still has not been sufficiently studied" (p. 399). Na verdade, a aquisição da linguagem pela criança, enquanto conquista de um objeto sobretudo auditivo e especialmente fugidio, não deixa de ser uma tarefa fascinante e árdua quando comparada com a conquista de qualquer outro objeto da vida real que seja permanente e que se preste a uma aproximação multissensorial (visual, tátil, auditiva, olfativa ou gustativa). Revela-se um trabalho bastante difícil, e sem dúvida moroso, extrair de uma sequência sonora fugaz - inicialmente ouvida, tudo 
leva a crer, como um continuum de ruído e música, num misto de consoantes, de vogais, do "movimento musical da frase" e da "canção do discurso" (GIROLAMIBOULINIER, 1993, pp. 8 e 33), - as unidades discretas que a integram, através de um trabalho de percepção categorial em diferentes escalas.

Entre nós, escreve-se da esquerda para a direita e lê-se seguindo uma direção análoga. Significa isso que quem escreve e lê nessa ordem teve de ter sido ensinado a seguir esse trajeto de alinhamento quando foi alfabetizado e de se ter consciencializado tanto do seu esquema corporal, conducente ao estabelecimento do sentido da direita e da esquerda, como da sucessão - esquerda/direita, em cima/em baixo - no espaço à sua volta e, muito em particular, numa folha de papel em branco ou escrita quando se trata de escrever e de ler.

No que se reporta à cadeia falada, que o mesmo é dizer à fala, o seu encadeamento não se opera num sentido único como na escrita. De resto, não será nos bancos da escola primária que se aprende que, quando se fala, se originam ondas de partículas de ar que chegarão aos ouvidos de quem estiver por perto seguindo um percurso não previamente definido e, porventura, só visível em ambiente laboratorial. No entanto, é imersa em cadeias faladas, audíveis por natureza, e não visíveis ou manipuláveis, distintamente do que se passa com grande parte dos objetos que a circundam, que a criança adquire, num ato de conquista feito de reconstituições continuadas, a língua a que está exposta, mediante exercícios de combinação precedidos dos de extração/categorização das unidades que compõem essas cadeias.

\section{A língua como objeto complexo}

A captação das sonoridades da cadeia falada em que a criança está imersa demanda, porém, um concomitante desenvolvimento da capacidade de representação que a leve a aperceber-se de uma relação gerada por convenção entre sons e realidade (SINCLAIR, 1974). É essa, de resto, seguindo a mesma fonte, a finalidade da função simbolização da língua como objeto complexo. Embora seja fundamental que a criança se aperceba da existência de uma relação entre os sons que ouve e os objetos ou acontecimentos que representam, vai ser imperioso, no seguimento da fonte aludida, que ela venha a aprender que essa relação não assenta por regra numa semelhança, numa motivação, conforme acontece com os gestos. A criança precisa, portanto, de se ir familiarizando com a arbitrariedade que governa essas relações. Consolida as ideias aduzidas, que tomaram por base Sinclair (1974), a seguinte passagem da sua autoria:

Le bébé doit comprendre que, lorsqu'on lui parle, les sons qu'il entend n’ont guère de ressemblance avec ce qu'ils représentent (...). Il doit se rendre compte qu'un même évènement peut donner lieu à des sons plus ou moins semblables à des occasions différentes et chez des personnes différentes. Il doit comprendre enfin qu'il n'y a pas de combinaison de sons précise pour chaque évènement isolé, que le langage ne constitue pas une sorte de liste de correspondances entre évènements et combinaisons de sons. (p. 6) 
O assunto será apresentado a seu tempo, mas impõe-se advertir que o que se passa nesta fase inicial da aquisição da linguagem oral pode fazer pensar no que virá a dar-se aquando da aprendizagem da linguagem escrita. Com as precauções que devem ser tomadas em circunstâncias como as presentes, poderá avançar-se que as sonoridades estarão para o que representam como a escrita está para o oral. Sem embargo, tal como acontece com o elo, com a "correspondência", entre combinação de sons e a realidade, também nas relações advenientes do código fonográfico, porventura com algumas exceções, não se deve esperar, consoante se lê no final do trecho transcrito acerca do oral, uma lista de correspondências pronta a servir, pré-estabelecida. Nada impede que se proponham correspondências nas duas situações, mas é de toda a conveniência que não se adotem visões simplistas. Essa precaução ecoa nas últimas palavras da citação supra. É quea cada acontecimento não corresponde uma combinação de sons precisos, posto que os sons relativos a um certo acontecimento podem variar em ocasiões diferentes, em resultado designadamente do contexto, e em pessoas diferentes, por força do modo de falar particular de cada indivíduo. Dessa diversidade marcada pela diferença, mas unicamente acústica/fonética e não fonológica/linguística, terá a criança de chegar ao invariante, ao denominador comum, ao que identifica como distintivo, através de uma operação de abstração.

\section{O lado transparente e o lado opaco da língua}

Será oportuno ver nessa operação inicial um primitivo do que será a correspondência propriamente dita, à semelhança do que decorre noutros conceitos?

Será essa operação, assente na ligação (correspondência) de combinações de sons a acontecimentos, instigadora da transparência de que se revestem as formas verbais aos olhos da criança quando esta comunica?

Será essa mesma operação que serve de fundamento à "glass window theory" (SOKHIN, 1988, p. 379) já explorada por Luria, à transparência da língua, de acordo com Cazden (1974), segundo a qual "a child perceives the object represented by a word without being aware of the existence of the word itself." (SOKHIN, 1988, p. 379)?

Será o caminho que a criança vai calcorreando no sentido da conquista, agora, do verdadeiro conceito de correspondência, graças à descentração cognitiva que nela se consuma, que lhe permitirá desenvolver a capacidade de separar a palavra do referente e consciencializar-se assim da opacidade, da realidade própria, dessa forma linguística, ultrapassando a fase da transparência?

Conceber a existência da palavra como objeto independente, opaco, constitui a base para o trabalho verbal que deve ser realizado a fim de que a língua possa ser desmontada e as palavras possam vir a ser analisadas numa vertente gráfica e noutra oral aquando da iniciação à escrita.

Transferindo o sentido etimológico de "esquizofrenia", termo tomado de empréstimo a McLuhan (1967), que o associa a uma consequência inevitável da 
alfabetização, para a palavra - qual "palavra dividida" -, pode afirmar-se que se está diante da melhor imagem para traduzir o que se passa na aprendizagem da leitura e da escrita, abduzindo a ideia de transparência que possa estar aglutinada à forma linguística.

Justifica-se, todavia, observar que essa "divisão" apontada para a alfabetização já terá começado a ser exercitada quando a criança brinca com a sonoridade das palavras em fases que precedem qualquer tipo de aproximação à aprendizagem da leitura e da escrita, o que faz lembrar e enfatizar o impacto que brincar causa na familiarização com o dito lado opaco da língua e consequentemente com o desenvolvimento/enriquecimento da linguagem (McCUNE-NICOLICH, CARROLL, 1981).

Este texto não é, porém, dedicado à aquisição da linguagem oral, mas sim às condições necessárias para uma entrada com sucesso no mundo da escrita, embora se objetive assinalar a repercussão que um oral bem exercitado pode ter numa iniciação à leitura e à escrita sem percalços.

A aquisição está usualmente vinculada à fala e a aprendizagem, por seu turno, à leitura e à escrita. Já que se aludiu a um oral bem exercitado como requisito para o sucesso na aprendizagem da leitura e da escrita, terá de se defender que também andará agregada à fala a possibilidade de ser aprendida.

\section{A importância para a criança da exposição a inputs verbais}

Uma criança que, desde a mais tenra idade, esteja perante inputs verbais numa quantidade e numa qualidade razoáveis e conviva assiduamente com a leitura, designadamente a indireta (PINTO, 1998), numa atitude de faz de conta que lê ao repetir o que alguém leu por ela previamente respeitando grupos de sentido, poderá experienciar uma relação mais estreita entre o oral e a escrita do que uma outra criança que coabite com um input verbal escasso e pobre quantas vezes também mascarado por ruídos de toda a ordem - e cuja rotina diária não inclua nem a leitura, nem o manuseio de material escrito.

Comenta Sinclair (1974) que a aquisição da linguagem, se bem que comparável à aquisição de estruturas cognitivas lógico-matemáticas ou do conhecimento físico, denota uma desigualdade basilar, já que demanda a exposição a um modelo.

Assinala a autora que a aquisição de línguas requer modelos objetivos e rigorosos. Para que a criança adquira a linguagem, prossegue Sinclair (1974), esta terá de estar obrigatoriamente exposta a inputs da língua que virá a falar. E falará tanto melhor essa língua, quanto mais rico, variado e elaborado for o input verbal que dela se lhe oferecer.

\section{A linguagem mais ou menos contextualizada}

Poderá ainda somar-se ao descrito o efeito que exercerá nas atividades escolares o convívio com uma linguagem mais ou menos contextualizada, 
linguagem essa que, dependendo do grau de (des)contextualização, ajudará a aproximar mais ou menos os dois modos de uso da língua: a fala e a escrita. Quanto mais a fala contar com o contexto não verbal, quanto mais mista for a sua sintaxe, ou seja, na definição de Slama-Cazacu (2002), uma sintaxe equiparável a uma mistura de cadeias verbais e de signos não verbais, tanto menos a fala se aproxima da escrita, que é na sua essência um modo de uso da língua descontextualizado.

$\mathrm{Na}$ trilha de Luria. queparafraseia Leonardo da Vinci para mostrar as similaridades entre a escrita e uma obra de arte(VOCATE, 1987), assume toda a pertinência conferir o devido crédito aos escritores que descrevem, porventura com mais subtileza e pormenor do que muitos especialistas da área, as características das conversas que se possam registar em famílias de meios sociais menos favorecidos. O excerto que se segue, saído da pena de Graciliano Ramos e constante da sua obra "Vidas secas", edição de 2017, é bem prova disso na medida em que nele se presencia uma projeção seminal do que é passível de se constatar num meio menos favorecido no que se reporta às conversas em família:

\begin{abstract}
A família estava reunida em torno do fogo. [...]. De quando em quando, estes [os meninos] se mexiam, porque o lume era fraco e apenas aquecia pedaços deles. Por isso não podiam dormir. Quando iam pegando no sono, arrepiavam-se, tinham precisão de virar-se, chegavam à trempe $e$ ouviam a conversa dos pais. Não era propriamente conversa: eram frases soltas, espaçadas, com repetições e incongruências. Às vezes uma interjeição gutural dava energia ao discurso ambíguo. Na verdade, nenhum deles prestava atenção às palavras do outro: iam exibindo as imagens que lhes vinham ao espirito, e as imagens sucediam-se, deformavam-se, não havia meio de dominá-las. Como os recursos de expressão eram minguados, tentavam remediar a deficiência falando alto. (pp. 63 e 64).

(Itálico da autora deste texto)
\end{abstract}

Os "meninos" desta família ouviam uma conversa que, para o autor, "Não era propriamente uma conversa". Não seria decerto a conversa que constitui o quotidiano das famílias de uma classe social mais escolarizada e com um nível de literacia mais elevado. Terá, contudo, de se admitir que será um tipo de conversa que espelha a rotina verbal de uma boa parte da população e que não se afasta radicalmente do que caracteriza um oral que se apoia no contexto (situacional ou de outra ordem).

As "frases soltas", as "repetições e incongruências" notadas por Graciliano Ramos caracterizam sem dúvida o oral praticado por muitas famílias, um oral quantas vezes mascarado por ruídos de toda a espécie e mesmo por elevações da voz em virtude da escassez de meios verbais, como adita o autor. Não é de descrer que esteja nessas conversas sem nexo e pobres lexical e estruturalmente a causa da resistência que a linguagem da escola oferece a crianças provindas de grupos onde essas conversas mais não são do que a linguagem que lhes serve de modelo e que elas acabam por tornar sua.

Muitas são as perguntas que emergem quando se tenta olhar de frente para o cenário traçado, visto que a Escola, face às inevitáveis diferenças individuais, não pode exigir do corpo docente apenas o cumprimento dos programas. 


\section{A Escola perante crianças com perfis distintos}

Como responde a Escola à heterogeneidade de perfis que lhe chegam todos os anos?

Como deve atuar um ministério com o pelouro da Educação para que o sucesso na aprendizagem da leitura e da escrita seja uma realidade e permita que cada criança prossiga o seu percurso escolar com o rendimento ensejado, impedindo os malquistos abandonos e retenções?

Quais são afinal as condições necessárias para que, independentemente do meio socioeconómico, se verifiquem bons resultados na aprendizagem da leitura e da escrita?

Estarão os responsáveis pela alfabetização da criança atentos ao que essa empresa pressupõe no plano cognitivo e neurológico, para além do verbal?

Estará a ser investido o necessário na pedra angular do ensino, a saber: no ensino pré-escolar?

Estará a criança a ser educada, mesmo em casa, de forma a sentir que existe uma continuidade entre o oral e a escrita e que esta última representa o acesso a um mundo por descobrir?

Como podem os especialistas em psicolinguística mostrar a quem detém uma relação mais próxima com as políticas educativas que a sua formação congrega conhecimentos que contribuiriam por certo para reduzir alguns dos problemas associados ao processo da alfabetização?

Este texto visa mostrar a relevância quer de um ensino pré-escolar de qualidade, quer da atuação dos pais que não cessam de conversar com os filhos, de lhes contar histórias e de lhes ler, no intuito de despertar e alimentar o seu potencial, preparando-os assim sem ansiedades e hesitações para a leitura e a escrita.

Afinal, não fez a criança já prova de ter sido capaz de superar uma etapa da sua vida talvez ainda mais espinhosa quando adquiriu a sua língua ou as suas línguas?

\section{II}

\section{O traçar de um percurso continuado entre o oral e a escrita}

Quando se fez menção neste texto à importância do input verbal, talvez não se tenha tornado suficientemente explícito que não basta expor a criança aos inputs verbais que lhe vão sendo disponibilizados diariamente, o que significaria uma relação unidirecional.

Posto isto, falta adicionar ao que foi aduzido que as conversas com as crianças, a leitura de histórias ou de outro material informativo e a narração de histórias deveriam ser, sem quaisquer reticências, atividades conjuntas. A criança deve ir colocando perguntas, deve ir objetando, deve ir completando o que lhe é apresentado, baseada no que já experienciou e no que acumulou através do que partilharam com ela por diferentes vias. Além disso, as produções da criança podem beneficiar com as oportunidades que as múltiplas conversas com 
terceiros, especialmente com adultos, lhe propiciam e com as correções que lhe fazem, desde que não seja intenção de quem corrige frustrá-la.

As leituras, as conversas e a narração de histórias que os pais praticam com os filhos devem, pois, ser exercidas de modo interativo e dialógico, o mesmo se esperando de educadores de infância, de outros adultos e de irmãos mais velhos quando são incumbidos dessas tarefas.

Uma vivência interativa com a linguagem em casa e/ou na pré-escola, baseada na leitura de histórias, de poemas e de notícias que despertem interesse na criança, na narração de contos e em conversas sobre as experiências vividas por cada um num passado mais ou menos recente, propicia abertura a um vocabulário alargado e preciso, à definição de palavras desconhecidas, a uma sintaxe mais complexa e estruturada, ao uso de elementos de coesão textual e de verbos cognitivos (achar, pensar, saber), bem como a um desprendimento do contexto, de interesse capital para a prática do discurso indireto e da descontextualização (ver MORGAN, GOLDSTEIN, 2004).

Pode afirmar-se, sem grande margem de erro, que uma criança que viva num ambiente literácito que contemple os aspetos enumerados entrará confortavelmente no mundo da escrita. Por seu turno, as crianças que não tenham vindo de um meio em que a literacia emergente é prática diária terão de esperar que o programa da pré-escola também tenha sido concebido a pensar nelas com a finalidade de equilibrarem desníveis de desempenhos verbais que possam ser detetados. Espera-se, por conseguinte, que o ensino pré-escolar preveja atividades, que até deveriam ser conjuntas, destinadas às crianças que evidenciem um desenvolvimento de linguagem distinto do das que provêm de meios ricos em práticas de literacia. Com a alusão feita a atividades conjuntas também entre crianças provindas de vários cenários literácitos, visa-se transmitir que uma "chave" para o nivelamento de perfis em matéria de linguagem, foco deste texto, pode também verificar-se à margem do programa delineado para estas faixas etárias. Conquanto os programas devam conter momentos de leitura, também da indireta (PINTO, 2017, p. 65-73), de narrações de histórias e de trocas de experiências vividas, em que se verifiquem sempre interação e partilha, a dita "chave" pode estar igualmente no convívio, que passa naturalmente pela linguagem, entre as crianças de proveniências diversas que frequentam a préescola. Nesta ocasião, tem cabimento partilhar com o leitor o pensamento da Professora Hermine Sinclair acerca da aprendizagem das crianças que frequentam os jardins de infância. Para esta psicolinguista, no cômputo do que aprendem as crianças nesses locais, representa uma boa percentagem o que as crianças aprendem umas com as outras. Serve esta breve nota para sobrelevar o significado do convívio entre crianças que, fruto das diversificadas vivências também verbais que transportam, muito concorre para o seu desenvolvimento.

A conveniência de um envolvimento verbal partilhado e interativo entre filhos/crianças e pais/adultos encontra-se expresso seminalmente na seguinte passagem de Zimmerman,et al.(2009): "Parents should strive to read and talk with children and not merely to them. Parent-child interactions are best when they are 
a two-way street" (p. 347). A ideia de se tratar de atividades que requerem dois sentidos é algo que todos os que lidam com crianças, numa atmosfera de literacia emergente, deviam ter bem presente, na medida em que afasta a possibilidade de nos destinatários em questão se vir a instalar uma atitude de passividade.

Passividade não se poderá, no entanto, entender como uma atitude face ao input verbal em que o sujeito que a ele está exposto não reaja de forma alguma. É clara prova do que se deixa dito o seguinte excerto da passagem supracitada de Graciliano Ramos: "Na verdade, nenhum deles prestava atenção às palavras do outro: iam exibindo as imagens que lhes vinham ao espírito, e as imagens sucediamse, deformavam-se, não havia meio de dominá-las." Ainda que os meninos daquela família não prestassem atenção às palavras, à conversa dos pais, nada impedia que essas palavras suscitassem nas suas mentes um desenrolar livre de imagens cuja razão de ser até a eles próprios escapava. De qualquer forma, estes meninos estavam tudo menos passivos. Quem sabe se essas imagens não se cruzavam com os seus sonhos e os transportavam para um sei lá onde geográfico ou temático.

Continuará a fazer sentido uma aproximação à linguagem nestes termos na época dos millennials?

Tudo leva a pensar que, independentemente do meio (eletrónico ou não) de chegar à informação e à comunicação, é de toda a utilidade que qualquer geração se inicie a uma abordagem à linguagem que lhe demande um comprometimento ativo, passível de lhe assegurar uma prática satisfatória de expressão oral, tão necessária à escrita, e uma capacidade de focagem meticulosa da atenção, imprescindível ao ato de ler. Relevante torna-se também não trocar, por hábito, a profundidade de análise pela celeridade de procedimento, o que obrigaria a que se incutisse o devido controle ao ritmo de atuação. É que, decorrente das rotinas, refrear o ritmo pode ser tão ou mais difícil do que acelerá-lo e essa desaceleração vai ser com certeza exigida ao longo da vida nas mais diversas situações. A leitura e a escrita serão bons exemplos dessa exigência. Não restarão dúvidas de que, neste particular, a escrita supera a leitura. A escrita é uma prática que exige tempo, que reivindica um esforço acrescido multissensorial e multicognitivo, cooperando numa escala superior para a aprendizagem (EMIG, 1977).

A importância que se dá nos dias de hoje à literacia digital tem toda a legitimidade, mas não deve ser descurada a literacia clássica, ou seja, a capacitação da criança para a descoberta desse outro lado da língua, o gráfico, que lhe permite saltar barreiras, aumentar o conhecimento, e aceder tanto ao mundo das novas tecnologias, como ao mundo da informação ou da ficção através da leitura e da escrita. A necessidade e o prazer têm de andar sempre lado-a-lado em matéria de leitura e de escrita. Atendendo a que a vertente necessidade parece andar sempre mais ligada a qualquer atividade, está nas mãos de quem educa despertar com veemência a vertente prazer, porque finalmente reside nessa forma de sentir a leitura e a escrita a abertura para "brincar" com a linguagem e, destarte, agarrá-la com outra destreza.

A musicalidade da língua - a "chanson du discours" (GIROLAMI-BOULINER, 1993, p. 33) -, audível em qualquer exemplar de fala ou de leitura em voz alta, 
emana acima de tudo - é essa uma possível opinião - da poesia, que se situa, por excelência, do lado da leitura prazer. O ritmo que transporta consigo cativa, sem dúvida, a criança. Ela pode sentir-se encantada ora com a leitura de poemas de autores célebres, ora com a simplicidade das letras de canções que lhe são cantadas/ ensinadas ou que ouve aqui e ali. Posta de lado a qualidade, se bem que seja crucial, sublinha-se, nesta oportunidade, o fascínio que exerce na criança o material verbal do poema ou das canções por via da sua sonoridade e das imagens que as suas palavras induzem. Umas crianças deixar-se-ão aliciar mais pelos sons do poema, outras crianças elegerão as imagens que dele sentem brotar. Outras, ainda, farão porventura como afirmou Sophia de Mello Breyner, numa entrevista que deu em 1995, a saber: "que aprendeu a gostar da poesia através da oralidade e que aprendeu os poemas visualmente" (apud PINTO, 2017, p. 76).

Começam, com grande probabilidade, a desenhar-se nessa altura os estilos mais auditivos, os mais visuais e os que conjugam os dois sentidos. Sem embargo, convém que a criança se ache atraída pelos sons e brinque com o que sente repetir-se, procurando depois jogar com essas sonoridades ou próximas delas para as inserir em contextos outros por si escolhidos/inventados. Este seria um passo basilar para ela se ir familiarizando com unidades infralexicais que a conduzirão mais tarde à consciência fonológica/fonémica, necessária à gestão do código fonográfico, que origina, acompanha ou segue essa consciência.

\section{A reciprocidade entre consciência fonológica e aquisição da leitura}

Este entendimento acerca da consciência fonológica vai na linha do comentário que Stanovich (1986) faz à sua instalação, admitindo que, relativamente à aquisição da leitura, essa consciência pode ser imaginada numa relação de reciprocidade.

Mesmo que haja propostas de modelos que privilegiem o estabelecimento de uma das duas relações causais, nomeadamente a relação entre a consciência fonológica e a aquisição da leitura, "independent of the status of the opposite causal link” (STANOVICH, 1986, p, 363), aceitar essas relações possibilita que se discuta o que se passa conceptualmente na criança, antes da sua entrada na escola ejá na escola. Antes da entrada na escola, quando lhe criarem ambientes que a façam apropinquarse, em boa parte brincando com o lado sonoro das palavras, das sonoridades que se libertam da sua língua, a criança estará a desenvolver indutivamente, a partir das suas vivências, conceitos espontâneos/básicos relacionados com os sons que integram as palavras. Deste modo, a criança ganha progressivamente sensibilidade para o que virá a ser mais tarde a consciência fonológica/fonémica. Na escola, por seu turno, faz a sua iniciação, com recurso à dedução, aos conceitos científicos, baseada no que lhe é transmitido no âmbito do código fonográfico com vista à aquisição/aprendizagem formal da leitura e da escrita.

Que os conceitos básicos se tenham desenvolvido com vista a que se registe um encontro "amigável" com os respetivos conceitos não espontâneos/científicos que se gerarem parece ser o que se almeja. 


\section{A Família e a (Pré-)escola enquanto agências de literacia}

Resta, então, esperar que, antes da aquisição/aprendizagem formal da leitura e da escrita, se forneçam à criança bases sólidas para que o encontro dos conceitos acima aduzidos se processe nas melhores condições. Ao ensino pré-escolar cabe, por isso, essa tarefa, bem como aos pais ou familiares que manifestem propensão para o fazer ou satisfação em aumentar na(s) criança(s) o interesse pela linguagem, lendo, narrando histórias ou episódios vividos, ou conversando, sempre num ambiente de diálogo. A família e a escola terão, pois, de cooperar para que o terreno seja propício ao sucesso. A escola terá, contudo, de estar atenta ao que cada família pode oferecer e ao que a sociedade civil faculta em prol da instrução que se pretende dar ao público em causa para que o processo de escolarização se concretize sem problemas e não se veja proliferar o analfabetismo funcional.

Uma criança exposta à leitura dar-se-á conta, mais cedo ou mais tarde, que quem lhe lê se serve de um suporte gráfico, por regra um livro, e que entre o que é lido e o que está escrito deve existir uma qualquer correspondência. Se, em simultâneo, for oferecida a essa criança, entre outras, a possibilidade de ler indiretamente, recorrendo à leitura indireta já introduzida, de ouvir amiúde poemas e até de os aprender de cor, de repetir à saciedade cantigas próprias da sua idade e de brincar com rimas ou outras sonoridades que integrem palavras verdadeiras ou imaginadas, também não lhe será decerto complicado acompanhar a maneira como se encontra edificada a língua que ela fala e que lhe falam em seu redor. Para isso, todavia, terá de se valer de duas operações de elevada relevância: a abstração e a simbolização. Na esteira do defendido por Girolami-Boulinier (1988), não deveria entrar no primeiro ano de escolaridade obrigatória nenhuma criança que não apresentasse capacidades de abstração e de simbolização.

Como se deve, portanto, levar uma criança em idade pré-escolar a dominar a abstração e a simbolização?

\section{A simbolização e a abstração: exigências do CALE}

No que concerne à leitura e à escrita, a simbolização - ato de representar, por exemplo, sonoridades por configurações gráficas -, apoiada na abstração na descentração - que a sustenta, é bem realçada por Girolami (2001) na sua bateria de testes "Ćntrôle des Aptitudes à la Lecture et à l'Écriture", conhecida por CALE. A esta bateria de testes vai ser dado, a partir de agora, o relevo que merece, por se tratar de um instrumento de avaliação inestimável não só para aquilatar se uma criança está ou não preparada para começar a aprender a ler e a escrever, mas também para saber em que tarefas se deve insistir no caso de esta ainda não estar no bom momento para ser alfabetizada.

O CALE, originalmente projetado para ser aplicado a crianças de língua francesa, possui tradução e adaptação ao português europeu com duas edições (GIROLAMI, 2006; 2018). É legitimo observar que se trata de um instrumento de avaliação que denota a preocupação que a sua autora sempre teve com a 
criança num todo. Nesta bateria está assimpatente um enfoque que se projeta numa esfera mais abrangente do que numa que se limite à leitura e à escrita. Constam, com efeito, do CALE testes com imposições de ordem multicognitiva que podem perfeitamente ocorrer em diferentes desempenhos da criança e não só nos respeitantes às tarefas de ler e de escrever.

A quantidade três é uma constante ao longo dos testes de perceção visual e auditiva que integram o CALE. Nele figuram testes que comportam sequências de três movimentos amplos, de três movimentos finos, de três elementos de cada qualidade fisiológica do som (duração, intensidade, timbre, altura, ritmo), de três formas geométricas com orientações diferentes, de três fonemas, de três sílabas, de grupos de sentido, e uma imagem correspondente a uma história em três atos. Cabe informar que o CALE demanda igualmente uma tripla operação para executar o que é pedido em cada teste. A criança tem assim de percecionar, reter e reproduzir/emitir/assinalar na ausência do modelo, de modo exato e na ordem apresentada, cada uma das diferentes tarefas solicitadas pelos testes do CALE. Para o fazer, a criança terá tanto de reconhecer (outra exigência cognitiva) a existência de um "agora/antes/depois" (GIROLAMI-BOULINIER, 1988, p. 149) nas sequências apresentadas, disposição temporal que ela terá também de discernir "nos atos simples da vida corrente" (p. 149), como de tomar consciência da correspondência espaço/tempo: "antes/depois, esquerda/direita" (p. 25). É justo acrescentar que a autora do CALE não se cansava de chamar a atenção para o impacto que têm as atividades que a criança executa na sua vida real, conquanto a temática em foco tenha mais a ver com a leitura e a escrita.

A título ilustrativo destacam-se agora dois atos banais do quotidiano, com significância, respetivamente, para a consciência do esquema corporal e para a motricidade fina, apontados por Andrée Girolami: 1) pôr a mesa, uma atividade que favorece a consciência do esquema corporal; e 2) apertar os cordões dos sapatos, uma atividade que treina a motricidade fina.

Quando, na segunda parte do CALE, se pede que a criança repita grupos de sentido, não se deve estranhar porque, em princípio, é mesmo dessa maneira que lemos e falamos e que a criança ouve falar à sua volta. Esta consciencialização é importante para que a criança não titubeie, não soletre, quando vier a ler. Acostumar a criança a lidar com grupos de sentido também lhe faculta a oportunidade de organizar o seu pensamento e a sua linguagem, no intuito de vir a ser compreendida e de compreender os outros.

\section{A pré-leitura, a pré-escrita e a pré-linguagem a partir do CALE}

Integram o CALE tarefas que, na tentativa de auscultarem as aptidões da criança para a leitura e a escrita propriamente ditas, são da ordem da pré-leitura, da pré-escrita e mesmo da pré-linguagem. No atinente à pré-leitura e à préescrita, serve-se Andrée Girolami de simbolizações que correspondem tanto a qualidades fisiológicas do som como a formas geométricas que se assemelham a partes de letras, reivindicando, como tal, um esforço de abstração baseado no 
distanciamento que se deve instalar entre a vertente auditiva do estímulo e a sua representação visual.

Um exemplo especial de tarefa de pré-leitura (silenciosa) e de pré-escrita é a que corresponde ao teste 3 do CALE referente a dez sequências de três formas geométricas - semicírculos e segmentos de reta - dispostas aleatoriamente e em diferentes orientações. A criança deve prestar atenção a cada uma das sequências de três formas, enquanto se mantêm as outras sequências ocultas, ao mesmo tempo que se lhe pede que olhe bem para a sequência de formas que se encontra à sua frente porque, quando achar que já a consegue reproduzir na ausência do modelo, esta será coberta com uma folha branca e ela terá de a desenhar numa folha de papel que se coloca ao lado do modelo oculto. O que a criança faz perante a sequência de três formas geométricas não é mais do que um ensaio de "leitura" (silenciosa), o que equivalerá ao que se pode chamar uma pré-leitura, uma vez que ainda não está perante uma sequência de letras. Quando se pede que reproduza essa sequência de formas, socorrendo-se do grau de motricidade fina que possui, acredita-se que a criança está a praticar um ensaio de "escrita", o que equivalerá ao que se pode chamar uma pré-escrita, posto que ela ainda não está propriamente a escrever. Frisa-se ainda que a criança já deve seguir a ordem espacial requerida pela nossa leitura e pela nossa escrita, ou seja, deve "ler" e "escrever" as sequências de formas da esquerda para a direita. A ocultação da sequência antes da sua reprodução permitirá que a criança se habitue a reter a imagem visual do modelo, retenção que terá de ocorrer mais tarde quando ela passar ao ato de escrita propriamente dito para que não cometa erros de ortografia. Operações como a reprodução de sequências de qualidades fisiológicas do som e a reprodução de formas geométricas constituem momentos de treino inestimáveis para que se instaure uma predisposição básica tendente, por um lado, à deteção de diferenças de sonoridades verbais e de representações gráficase, por outro lado, à sensibilização para o que subjaz ao código fonográfico.

Revela-se pertinente ressaltar como as noções de classe e de número são alcançadas em torno da idade em que se inicia a ler e a escrever, o que faz pensar fortemente na psicolinguística, enquanto ciência que procura explicar como se processa a linguagem oral e também escrita.

De regresso ao CALE, nele se acha uma prova que fornece informação expressiva acerca da capacidade que a criança tem de narrar - depois de ocultada uma imagem que teve diante dos seus olhos o tempo de que necessitou para a reter - uma história com base num suporte pictórico em três episódios - de novo a quantidade três -, apresentado de modo muito esquemático. A apresentação simplificada do conteúdo da história - personagem e enquadramento - tem como objetivo fazer com que a criança não se prenda a pormenores, enumerandoos, e não atrase a passagem de um episódio a outro, valorizando a descrição em detrimento da narração. Ocultar a imagem também objetiva reforçar que a criança não se fixe em cada um dos episódios e avance para o seguinte, ou seja, atinja a narração e não se fique pela descrição. A passagem da cronologia estática, descrição, à cronologia dinâmica, narração (GIROLAMI-BOULINIER, 
1984), pode assim ser avaliada e mostrar como é significativo que a criança esteja habituada a que lhe contem histórias, a que lhe narrem passagens vividas a fim de que se familiarize seja com a linguagem que é usada, com todos os elementos de coesão necessários, seja com a estrutura clássica de uma história, que no geral encerra um raciocínio que comporta uma relação causa-efeito.

A quantidade três esteve sempre presente. Como atuar com crianças que ainda não conseguem reproduzir com sistematicidade sequências de três elementos?

Quando isso suceder, volta-se à quantidade com a qual a criança se sinta mais à vontade. Deve regressar-se, neste caso, à quantidade dois e, quando esta estiver bem instalada, passa-se então à quantidade três. É aconselhável que a criança não seja instada a realizar o que ainda não consegue. Evocaria aqui o que recomendava Girolami-Boulinier. Esta reconhecida ortofonista não cessava de advertir que não se devia combater o insucesso nem com o material que a ele conduziu, nem no local onde ocorreu. Seria bom que todos tivessem conhecimento deste sábio alerta.

\section{Apontamento de fecho}

Alguém que ouse afirmar que a linguagem, seja ela oral ou escrita, e a sua aquisição ou aprendizagem podem ser abordadas sem um conhecimento plural aprofundado não deve estar ao corrente do que esses processamentos implicam.

Não basta que, através de um estudo, se constate um dado desempenho verbal num determinado grupo etário. Também é fundamental explicar como essa população chegou a esse desempenho. O porquê terá de estar sempre presente, em razão de, antes de mais nada, ser preciso saber explicar o que se obteve ou não em função do desenho traçado para o estudo realizado.

No presente texto, optou-se por observar o que se passa nos bastidores da iniciação ao mundo da escrita tomando por base a psicolinguística genética. Mencionar a abstração, a simbolização, a quantidade três, as noções de número, de classe e as relações ordinal e de equivalência como relevantes para a aprendizagem da leitura e da escrita só faz mesmo sentido quando se possui uma formação em psicolinguística, sobretudo genética. Vale, destarte, saber o que representa o desenvolvimento operatório no processo de aprendizagem da leitura e da escrita. Talvez não seja por acaso que a criança atinge o período operatório concreto e, neurologicamente, a maturidade certa do território de Geschwind (FITZAKERLEY, 2015) numa idade que corresponde grosseiramente à entrada na escola primária. Faltará ainda aditar a base sociológica às aprendizagens aludidas (SLAMA-CAZACU, 1979). Neste ponto, não foi parco este texto em apontar a importância do input verbal a que a criança está exposta e em listar tarefas que devem ser praticadas no seio familiar ou na pré-escola de modo interativo e partilhado no intento de se granjear o ambiente de literacia emergente recomendável e mais compaginável com a linguagem própria da Escola.

Tudo o que até aqui se expôs foi explorado, dentro do espaço possível, na primeira parte deste texto. Nela foram expostas as várias noções essenciais na ótica operatória 
para que a abordagem à entrada no mundo da escrita pudesse estar subordinada à psicolinguística genética. Também não se deixaram de lado os modelos de linguagem a que as crianças estão habituadas e as recomendações que devem ser tidas em conta a esse respeito. Já na segunda parte serviu a bateria de testes da autoria de Andrée Girolami - o CALE - para mostrar como avaliar as aptidões da criança para a leitura e a escrita em moldes que abracem a criança num todo.

Advoga-se, sem reticências, neste escrito a importância de uma boa política a nível pré-escolar e de um ambiente familiar que vá preparando a criança para sentir que a leitura e a escrita lhe facultarão o ingresso num mundo que não cessará de a surpreender.

\section{Referências}

CAZDEN, Courtney B. Play and metalinguistic awareness: one dimension of language experience. The Urban Review, v.7, n.1, p. 28-39, 1974.

ELKONIN, D. B. How to teach children to read. In: Downing, John A. (Ed.). Cognitive psychology and reading in the U.S.R.R. North-Holland: Elsevier Science Publishers B. V., 1988, p. 387-426.

EMIG, Janet. Writing as a mode of learning.College Composition and Communication, v. 28, n. 2, p. 122-128, 1977.

FITZAKERLEY, Janet. Cortical language areas.3pp. University of Minnesota, Medical School Duluth, 2015.Documento disponível em http://www.d.umn.edu/ jfitzake/ Lectures/DMED/SpeechLanguage/CorticalS_LAreas/CorticalLanguageAreas. html, acesso 2 fev. 2019.

GINSBURG, Herbert; OPPER, Sylvia.Piaget's theory of intellectual development.2nd edition. Englewood Cliffs, New Jersey: Prentice-Hall, Inc., 1979.

GIROLAMI, Andrée. Contrôle des aptitudes à la lecture et à léeriture. Montreuil: Éditions du Papyrus, 2001.

GIROLAMI, Andrée. Controle das aptidões para a leitura e a escrita, 1. ${ }^{a}$ edição. Tradução e Adaptação de Maria da Graça Castro Pinto e João Veloso. Coleção CAPFLUP. Porto: Faculdade de Letras da Universidade do Porto, 2006.

GIROLAMI, Andrée. Controle das aptidões para a leitura e a escrita, 2. ${ }^{a}$ edição. Tradução e Adaptação de Maria da Graça Castro Pinto e João Veloso. Coleção CAPFLUP. Porto: Faculdade de Letras da Universidade do Porto, 2018.

GIROLAMI-BOULINIER, Andrée. Les niveaux actuels dans la pratique du langage oral et écrit. Paris: Masson, 1984.

GIROLAMI-BOULINIER, Andrée. Les premiers pas scolaires. Acquisitions indispensables pour prevenirléchecscolaire. Issy-les-Moulineaux: Editions et Applications Psychologiques (E.A.P.), 1988.

GIROLAMI-BOULINIER, Andrée. L'apprentissage de l'oralet de l'écrit. Collection “Que sais-je?”, 2717. Paris: Presses Universitaires de France, 1993.

MASSON, Steve. Étude des mécanismes cérébraux lies à lexpertise scientifique en éléctricité à l'aide de l'imagerie para résonance magnétique fonctionnelle. Thèseprésentéecomme exigence partielle du doctoratenéducation. Montréal: Université du Québec à Montréal, 2012.

McCUNE-NICOLICH.Lorraine; CARROLL, Shelley.Development of symbolic play. Implications for the language specialist. Topics in Language Disorders, v.2, n.1, p.1-15,1981. 
McLUHAN, M. La galaxie Gutenberg. Face à lère électronique. Les civilisations de lâge oral à l'imprimerie. 4e édition. Paris: Mame, 1967.

MORGAN, L.; GOLDSTEIN, H. Teaching mothers of low socioeconomic status to use decontextualized language during story book reading. Journal of Early Interventions, v.26, n. 4, p. 235-252, 2004.

PIAGET, Jean. La formation du symbole chez lenfant. Imitation, jeuetrêve, image et représentation. Sixièmeédition. Neuchâtel-Paris: DelachauxetNiestlé, 1976.

PIAGET, Jean. Comments on Vygotsky's critical remarks. Archives de Psychologie, v. XLVII, n. 183, p. 237-249, 1979.

PINTO, Maria da Graça L. Castro. Saber viver a linguagem. Um desafio aos problemas de literacia. Porto: Porto Editora, 1998.

PINTO, Maria da Graça Castro. Nos bastidores da iniciação à entrada no mundo da escrita. Do CALE aos pressupostos de ordem cognitiva e neurológica. Porto: FLUP/CLUP, 2017.

RAMOS, Graciliano. Vidas Secas. 135. a edição. Rio de Janeiro: Editora Record, 2017.

SINCLAIR, Hermine J. Lacquisition du langage d'un point de vuePiagetien. Folia Phoniatrica, v. 26, p. 1-12, 1974.

SLAMA-CAZACU, Tatiana. Psicolingüística aplicada ao ensino de línguas. São Paulo: Livraria Pioneira Editora, 1979.

SLAMA-CAZACU, Tatiana. Aula proferida na Faculdade de Letras da Universidade do Porto, a 28 de fevereiro de 2002.

SLAMA-CAZACU. Tatiana. Psycholinguistics, where to in the 21st century? In: Arabski, Janusz (Ed.). Challenging tasks for psycholinguistics in the new century. Katowice: University of Silesia, 2007, p. 77-85.

SOKHIN, F. A. Preschoolers' awareness of speech and readiness for learning literacy. In: Downing, John. A (Ed.). Cognitive psychology and reading in the U.S.R.R. North-Holland: Elsevier Science Publishers B. V., 1988, p. 379-386.

STANOVICH, Keith E. Mathew effects in reading: some consequences of individual differences in the acquisition of literacy. Reading Research Quarterly, v. XXI, n. 4, p. 360-406, 1986.

VOCATE, Donna R. The theory of A. R. Luria. Functions of spoken language in the development of higher mental processes. Hillsdale, New Jersey: Lawrence Erlbaum Associates, Publishers, 1987.

VYGOTSKY, Lev S. Thought and language. Cambridge, Massachusetts: The M.I.T. Press, 1962.

ZIMMERMAN, F. J.; GILKERSON, J.; RICHARDS, D. A.; XU, D.; GRAY, S.; YAPANEL, U. Teaching by listening: the importance of adult-child conversations to language development. Pediatrics, v.124, p. 342-349, 2009.

Recebido em: 19/02/2019

Aceito em: 30/07/2019 